\title{
O LIMIAR DA PRODUÇÃO DO CONHECIMENTO DA ADMINISTRAÇÃO PÚBLICA ACERCA DO ESTADO
}

\author{
Rossi Henrique Soares Chaves ${ }^{1}$ \\ Janaynna de Moura Ferraz ${ }^{2}$ \\ Bárbara Katherine Faris Biondini ${ }^{3}$
}

\section{RESUMO}

O intento deste trabalho consiste em perscrutar o conhecimento produzido na Administração Pública, no período entre 1970 até 2017, partindo do pressuposto que o Estado moderno corresponde a uma mediação determinante na sociabilidade capitalista. Procedemos, em um primeiro momento, uma análise do conteúdo no campo para mapear suas características principais quanto ao fazer científico e à abordagem teórica acerca do Estado. No segundo momento, aprofundamos a reflexão submetendo tais achados à crítica da economia política, para delinear suas mediações e determinantes. A investigação preliminar aponta que o Estado é tratado com uma condição de naturalização, de maneira que as produções científicas tendem, em sua maioria, a centrar suas análises nas abordagens gerenciais (técnicas/avaliações), cujos trabalhos de viés mais crítico se destinam tão somente a apresentar possibilidades de reforma e/ou melhoria da gestão. A conclusão ratifica a necessidade de avançar quanto à forma de produzir conhecimento na Administração Pública, cuja materialidade e a historicidade devem assumir um papel central enquanto categorias com capacidade de apreensão do real, buscando contribuir, desse modo, com mudanças qualitativas no estado das condições concretas de vida da sociedade.

1 Graduação em Ciências Econômicas e Administração Pública ambos pela UNIFAL-MG. Mestre e Doutorando em Administração pela UFMG na linha de Estudos Organizacionais e Sociedade. Membro do Núcleo de Estudos Críticos Trabalho e Marxologia (NEC-TraMa). Professor substituto da UFJF/GV.

2 Professora adjunta do Departamento de Ciências Administrativa da Universidade Federal do Rio Grande do Norte. Doutora em Administração (CEPEAD/UFMG), mestra em Administração (CEPEAD/UFS) e bacharela em Administração (FANESE/SE). Atualmente é vice-diretora gestão 20182020 da Sociedade Brasileira de Estudos Organizacionais e pesquisadora - Núcleo de Estudos Críticos Trabalho e Marxologia. Atua principalmente nos seguintes temas: ciência e ideologia, crítica da economia política, crítica à prática empreendedora, capitalismo brasileiro e estudos organizacionais.

3 Doutoranda e Mestre em Administração pelo Centro de Pós-Graduação e Pesquisas em Administração - CEPEAD/UFMG. Graduada em Psicologia pela Universidade Federal de Minas Gerais. Vinculada aos grupos de pesquisa Núcleo de Estudos Críticos Trabalho e Marxologia (NEC-TraMa), Economia Política do Poder em Estudos Organizacionais - EPPEO (UFPR), TRAMA - Trabalho e Marxismo (UFJF) e ao Laboratório de Estudos sobre Trabalho, Sociabilidade e Saúde - LETSS (UFMG). 
Palavras-Chave: Estado; Administração pública; Produção de conhecimento; Ideologia.

\section{EL UMBRAL DE LA PRODUCCIÓN DE CONOCIMIENTO EN LA ADMINISTRACIÓN PÚBLCA SOBRE EL ESTADO}

\section{RESUMEN}

El propósito de este artículo es examinar el conocimiento producido en la Administración Pública, de 1970 a 2017, suponiendo que el estado moderno corresponde a una mediación determinante en la sociabilidad capitalista. Al principio, procedemos a un análisis del contenido en el campo para mapear sus características principales con respecto a la actuación científica y el enfoque teórico sobre el estado. En segundo lugar, profundizamos la reflexión al someter tales hallazgos a la crítica de la economía política para delinear sus mediaciones y determinantes. La investigación preliminar señala que el estado se trata con una condición de naturalización, por lo que las producciones científicas tienden a centrarse principalmente en enfoques de gestión (técnicas / evaluaciones), cuyos trabajos de sesgo más críticos son solo Posibilidades actuales de reforma y / o mejora de la gestión. La conclusión confirma la necesidad de avanzar en la forma de producir conocimiento en la Administración Pública, cuya materialidad e historicidad deberían asumir un papel central como categorías capaces de aprehender lo real, contribuyendo así con cambios cualitativos en el estado de las condiciones de vida concretas de la sociedade.

Palabras clave: Estado; Administracion publica; Producción de conocimiento; Ideología

\section{THE THRESHOLD OF KNOWLEDGE PRODUCTION IN PUBLIC ADMINISTRATION ABOUT THE STATE}

\section{ABSTRACT}

The purpose of this paper is to examine the knowledge produced in the Public Administration, from 1970 to 2017, assuming that the modern state corresponds to a determinant mediation in capitalist sociability. At first, we proceed to an analysis of the content in the field to map its main characteristics regarding the scientific doing and the theoretical approach about the state. Secondly, we deepen the reflection by submitting such findings to the critique of political 
economy to delineate its mediations and determinants. Preliminary research points out that the state is treated with a condition of naturalization, so that scientific productions tend to focus mostly on management approaches (techniques / evaluations), whose most critical bias works are only present possibilities for reform and / or improvement of management. The conclusion confirms the need to advance the way of producing knowledge in the Public Administration, whose materiality and historicity should assume a central role as categories capable of apprehending the real, thereby contributing with qualitative changes in the state of society's concrete living conditions.

Keywords: State; Public administration; Knowledge production; Ideology.

\section{INTRODUÇÃO}

A produção de conhecimento no campo da Administração Pública (AP) tem crescido e se consolidado nas últimas duas décadas. Segundo Justen e Gurgel (2015), tal movimento decorre principalmente do aumento do número de concursos públicos e da criação de novas carreiras na gestão do Estado, como analista e gestor de políticas públicas, de planejamento e orçamento, por exemplo. Coelho (2019) menciona que apenas entre o ano de 1995 e 2006 o MEC registrou um aumento de 13 para 96 (sendo 52 bacharelados, ofertados em sua maioria por instituições privadas) cursos em administração pública, para Coelho (2019) essa fase é denominada como embrionária e culminou, mais recente, na criação do Campo de Públicas ${ }^{4}$. Registre-se igualmente a expansão, na última década, dos cursos de graduação e pós-graduação que discutem o Estado a partir de diferentes perspectivas epistemológicas, Coelho (2019) estima que atualmente existem cerca de 250 cursos de graduação no Campo de Públicas, totalizando aproximadamente cerca de 50 mil matriculados.

\footnotetext{
4 "Campo de Públicas é uma expressão utilizada (...) para designar, essencialmente, um campo multidisciplinar de ensino, pesquisa e fazeres tecnopolíticos (...) que se volta para assuntos, temas, problemas e questões de interesse público, de bem-estar coletivo e de políticas públicas inclusivas (...) na busca do desenvolvimento socioeconômico sustentável, em contexto de aprofundamento da democracia." (PIRES, SILVA, FONSECA, VENDRAMINI e COELHO, 2014, p. 3).
} 
Por um lado é salutar que a academia brasileira venha se interessando mais pela questão do Estado - especialmente em tempos de despolitização das massas -, por outro lado, faz parte das atribuições da comunidade científica comprometida com o avanço do conhecimento, a tarefa de avaliar a qualidade, a destinação e o papel que tal produção tem sobre a sociedade. Sendo assim, será que a Administração Pública tem conseguido avançar quanto à apreensão da realidade sobre o Estado em sua profunda relação com a produção da vida hodierna?

Nessa direção, nosso objetivo consiste em perscrutar o conhecimento produzido na Administração Pública, no período entre 1970 até 2017, partindo do pressuposto que o Estado moderno corresponde a uma mediação determinante na sociabilidade capitalista. Frisamos que embora não haja em Marx uma teoria geral do Estado, suas reflexões propiciam o apontamento de determinações históricas sobre a estrutura estatal moderna que possibilitam acompanhar a gênese, o desenvolvimento e as tendências dessa forma particular de sociabilidade, a sociedade capitalista.

Nosso primeiro excurso consistiu em investigar os estudos bibliométricos de Silva, Trottmann, Coelho e Sarti (2013), Keinert (1994); Fleury (2003); Hocayen-da-Silva, Rossoni e Ferreira-Júnior (2008); Peci, Ribeiro, Rodrigues e Forzani (2011); Martins (2007); Ribeiro (2014); Smolski, Dalcin, Visentini, Bamberg e Kern (2017); Paes-de-Paula, Maranhão, Barreto e Klechen (2010) e Justen e Gurgel (2015), com a finalidade de mapear as linhas gerais da produção do conhecimento em AP. Enquanto na segunda parte do trabalho, realizamos um levantamento de artigos publicados nos anais de três grandes eventos científicos: Encontro da Associação Nacional de Pós-Graduação e Pesquisa em Administração (EnANPAD), Encontro de Administração Pública e Governança (EnAPG) e Encontro de Estudos Organizacionais (EnEO) e também na Revista de Administração Pública (RAP), seguido de uma análise em profundidade da relação entre ideologia e produção científica.

Dentre os pressupostos que guiaram nossa investigação, seguimos Mészáros (2008) em sua abordagem quanto ao tratamento ideológico, neste caso, voltado para nosso objeto de estudo, o Estado. Para tanto, buscamos compreender se os pesquisadores do campo: a) 
assumem o Estado como um objeto natural e, portanto incontornável, buscando, assim, conservar sua forma tradicional; b) assumem o Estado como um objeto administrável, passível de reforma, melhorias e, por isso, a AP poderia contribuir com a maior eficiência da coisa pública, ou, por fim; c) visam a superação do Estado dado seu caráter de impotência em face da sociabilidade vigente.

Essa pesquisa se justifica pelos embates das últimas décadas - período investigado, de 1970 até os dias atuais - quanto ao que seria o "papel do Estado", e as discussões sobre "crise econômica" persistente, "crise democrática"; "neoliberalismo", além do crescimento em nível global da dívida pública. Afinal, o Estado destes tempos se submete aos preceitos da gestão empresarial?

Ademais, a revisão crítica da literatura contribui com uma visão mais ampla da delimitação do campo da Administração Pública. Lastreados em Mészáros (2006), sustentamos que a práxis científica, em seu nexo indissociável com a produção da vida, pode reforçar o status quo do papel do Estado, naturalizando-o e, na esteira positivista, poderia mesmo consertá-lo ou curá-lo. Nossa propositura é no sentido de aprofundar tais limiares. Para isso, devemos transformar a forma e a natureza da práxis científica, ao investigar o objeto para inquiri-lo em suas múltiplas mediações, buscando suas determinações sociais e, desse modo, a essência das relações sociais hodiernas mediadas pelo Estado.

0 artigo encontra-se organizado da seguinte maneira: após esta breve introdução, discutimos a necessidade de se evidenciar a particularidade do Estado moderno na produção do conhecimento, a partir de trabalhos realizados que tiveram como foco a análise de produção de conhecimento. Em seguida discutimos a relação entre ideologia e produção científica a partir das contribuições de Mészáros. Por fim, apresentamos nossas considerações finais sobre o tratamento do Estado capitalista a partir da produção científica investigada. 


\section{A PRODUÇÃO DO CONHECIMENTO SOBRE O ESTADO NA ADMINISTRAÇÃO PÚBLICA}

Neste tópico apresentamos uma síntese do mapeamento realizado no campo da Administração Pública. Dentre as principais considerações destacamos:

- Há uma tendência em publicar artigos de abordagem aplicada (baseados em modelos matemáticos) em detrimento de trabalhos teóricos e/ou ensaísticos (FLEURY, 2003; HOCAYENDA-SILVA et al., 2008; e SMOLSKI et al., 2017).

- A abordagem qualitativa é considerada um "problema", que segundo Hocayen-da-Silva et al. (2008, p. 688), expressa "a fragilidade e imaturidade do campo e que, sendo assim, o 'amadurecimento' está diretamente ligado com o crescimento da utilização de métodos quantitativos".

- Menos de $8 \%$ dos artigos sobre AP podem ser considerados críticos, e para os autores, “críticos" seriam os estudos que fazem oposição ao management (PAES-DE-PAULA et al., 2010).

- Há 10 artigos considerados como “clássicos RAP”, todos eles sobre reformas administrativas e novos modelos de gestão (MARTINS, 2007).

- O problema principal da produção do conhecimento em AP seria sua fragilidade e fragmentação, caracterizado pelas seguintes ocorrências: a) falta de identidade própria; b) falta de delimitação; c) falta de rigor metodológico; d) vale-tudo temático (variedade de temas); e) modismo (pesquisas pautadas na agenda governamental); f) autorreferência (por possuir poucos pesquisadores); g) falta de apoio institucional (pouco investimento em ensino e pesquisa) (SILVA et al., 2013).

Algumas reflexões preliminares nos permitem expor tal cenário a partir de duas considerações: sobre o método científico e sobre a epistemologia.

No que tange ao método, aparentemente se confunde empiria com objetividade. "Estudos de casos" tem potencial explicativo delimitado. O fato de um ou mais casos confirmarem o que foi previsto por uma teoria não representa que seja uma explicação da realidade, mas a aparência dela. Não se trata de uma crítica ao indutivo, trata-se de uma crítica à centralidade do sujeito (o pensador da teoria) sobre o objeto que deve "encaixar" na referida explicação teórica. Assim, embora esses estudos se apresentem como objetivos, na verdade, refletem a subjetividade do pesquisador que usa o objeto para confirmar suas formulações. 
Isso ocorre pois há uma prioridade do método sobre o objeto, caracterizando, assim, uma imputação subjetiva e gnosiológica em relação à realidade objetiva. Tais perspectivas desconsideram que a elevação do primado empírico como o acesso único à realidade tende a ignorar as mediações e também a isolar os problemas sociais, pois os particiona em disciplinas (economia; política; ciências sociais, etc.), o que limita o avanço da compreensão do real, visto que, dada a fragmentação do objeto para atender a empiria vulgar, perde-se a possibilidade de acesso à raiz de suas causas, isto é, falta a apreensão da totalidade. Não pretendemos dizer com isso que o empírico não seja importante, pois ele o é, contudo, é preciso resgatar que a realidade é mais complexa que verificações parciais e aparentes.

Quanto à epistemologia, aparentemente a defesa do campo é pela existência e manutenção de paradigmas, que por si só já representa um limite (FERRAZ, CHAVES e FERRAZ, 2018). Entre eles, haveria uma preponderância dos paradigmas Gerencialismo (29,60\%) e Governança (28,4\%) (KEINERT, 1994; PECI et al., 2011).

Neste caso, é necessário pontuar a limitação do tratamento kuhniano da produção científica segundo paradigmas, por "particionar" a realidade segundo critérios lógicos e metodológicos previamente estabelecidos, o que torna restrito mensurar a "maturidade" de um campo científico, pois ele não pode ser reduzido a esquemas conceituais ou lógicos relegando o tratamento da realidade social em si a um pano de fundo secundário. No tópico a seguir avançamos sobre o conteúdo do conhecimento produzido.

\section{O TRATAMENTO DO PÚBLICO E DO PRIVADO NA ADMINISTRAÇÃO PÚBLICA}

A questão do público e privado tem sido uma confusão recorrente no que se refere à sua distinção e os interesses que a permeiam. A ocorrência mais frequente consiste em tratar o "público" como exclusivo do poder público estatal, em oposição ao privado, conforme Meirelles, Filho e Burle (2016), Meny e Thoening (1992) e Howlett, Ramesh e Perl (2013).

A fragilidade de tal abordagem decorre da tendência a simplificar a ação do Estado em sua dinâmica social - a sociabilidade capitalista - naturalizando, à guisa de exemplo, a função 
do Direito ao proporcionar a manutenção das relações de exploração (direito do trabalho) e a manutenção da propriedade privada dos meios de produção (direito empresarial). Pois, se por um lado há quem sustente que o fortalecimento do Estado de direito é o caminho para o progresso social, por outro lado tais explicações não deveriam ser obnubiladas das condições materiais dessas relações. Sendo assim, a AP ignora (ou oculta) o modus operandi das relações sociais capitalistas e estabelece o Estado como abstração frente ao indivíduo.

Desse modo, acerca de uma possível "teoria do Estado", Mészáros (2015), sustenta que, por vezes, as investigações dos problemas do Estado são reduzidas às leis e ao direito.

\begin{abstract}
O problema sério a esse respeito é que a identificação do Estado com a lei e o direito distorce fundamentalmente e racionaliza e justifica apologeticamente a realidade de fato existente do Estado ao projetar - explícita ou implicitamente - a coincidência ideal de lei legítima na coincidência de 'lei' e 'Estado', que está longe de ser obviamente inquestionável. Pois o Estado realmente existente - incluindo, claro, o moderno 'Estado democrático' capitalista - é caracterizado não só por lei e direito, mas também pela absolutamente destrutiva ilegalidade e assim pelo diametralmente oposto lei legítima. (MÉSZÁROS, 2015, p. 47; grifos do autor).
\end{abstract}

Tal tratamento teórico contribui com o reforço na busca para explicações dentro dos limites de diferentes arranjos e formatos para o Estado moderno, sem, contudo, questionar, antes, qual seu papel nas mazelas da vida hodierna, alinhado à função que o direito cumpre.

No final das contas, tais teorias operam como uma "exigência absoluta para assegurar e proteger permanentemente a produtividade do sistema" (MÉSZÁROS, 2011, p. 106). Tanto o é que a cada nova agudização de crise econômica (redução da capacidade de acumular mais valor), o Estado entra em cena para garantir a "justiça do mercado", assim como, contraditoriamente, perde a credibilidade entre a classe trabalhadora. E neste caso, as leis perdem seu efeito.

Sobretudo, o Estado é referido como representante dos interesses universais/gerais que abrangem todas as esferas da sociedade, como podemos ver em Heidemann (2009) e Secchi (2010), no qual até mesmo empresas privadas, ONGs, e fundações seriam consideradas capazes de promover o alcance de um interesse público. 
A questão, porém, é que filantropia, reparação dos danos ambientais, contratação de menores aprendizes etc. têm sido meios para obtenção de lucro privado. Por isso, fala-se em sustentabilidade e responsabilidade social também em empresas privadas. Mas não é preciso ir muito longe para constatar a limitação dessas ações: tais empresas atuam, quando efetivamente atuam, até onde é exigido legalmente. Portanto, em última instância, o que há de "social" trata-se de coerção do Estado (e toda a complexidade que envolve essa ação).

Nesse mesmo sentido são as propostas de avaliação de políticas públicas (SCHNEIDER, 2009, DYE, 2009, SECCHI, 2010, HOWLETT, RAMESH e PERL, 2013), em que diferentes critérios são estabelecidos para que se possa mensurar a dimensão de tais políticas frente aos problemas sociais. Entre esses, Secchi (2010) aponta a) economicidade; b) eficiência econômica; $c$ ) eficiência administrativa; $d$ ) eficácia; $e$ ) equidade. Observemos que os critérios econômicos, como $a$ e $b$, se restringem à operação financeira (recursos utilizados, produtividade), enquanto $c$ e $d$ se referem ao âmbito gestionário (prazos, entregas, alcance), já o e está relacionado com a distribuição da política pública.

Para demonstrar os limites da atuação do tratamento da AP a partir de tais pressupostos, imaginemos, por exemplo, uma política pública de erradicação da pobreza. Embora seja uma pauta recorrente nos programas de diversos governos, é possível afirmar que se trata efetivamente de uma proposta? 0 que tem se observado é a prioridade da gestão pública "salvar o Estado da crise" (que não cessa, obviamente) enquanto a pobreza pode esperar a situação melhorar um pouco.

Ora, como erradicar a pobreza se tal problema jamais passaria do crivo da eficiência econômica? Para erradicar a pobreza seria necessário, ao mesmo tempo, combater os fatores que a ocasionam, e fazer isso consistiria necessariamente em mexer na produção da riqueza que, por sua vez, segue sendo apropriada privadamente por uma pequena parcela da população. 
Uma análise histórico-materialista aponta que a pobreza, na verdade, é resultado imediato de uma lógica social de concentração, sendo, inclusive, importante que ela se perpetue para que as relações capitalistas de produção se mantenham (MARX, 2013). Por exemplo, ao analisar projetos de políticas públicas de geração de trabalho e renda, Ferraz (2015, p. 139) constatou que esses alavancam o movimento de reprodução do capital, entre outros motivos, ao recriar "a superexploração do trabalho no âmbito do movimento global do capital, colaborando para a diminuição do preço da mercadoria força de trabalho".

Noutro caso, Engels (2015), ao tratar das políticas públicas de habitação para a classe trabalhadora na Inglaterra e na França no século XIX, mostrou como elas foram importantes para a rentabilidade do capital privado investido como também para a expansão industrial. Nada muito diferente do que ocorre com o programa Minha Casa Minha Vida.

Em síntese, esse modo de fazer científico nos mostra que os esforços dos Estados sobre a pobreza consistiram em reduzir as desigualdades, via redistribuição entre os estratos sociais que vivem da renda salário, para acelerar o ciclo do capital. Isso pode ocorrer independentemente da posição ideológica de um Governo, pois a ação do Estado tem sido mediar os interesses privados daqueles que o controlam, mantendo, quando necessário, as contradições sociais em estado latente a fim de reduzir a possibilidade de insurgências.

Assim, percebemos que as pesquisas ignoram (por opção ou negligência) que os problemas sociais, foco das políticas públicas, são resultados imediatos da própria dinâmica social do capital. o que explica o fato de a "mensuração dos resultados" ser uma das preocupações centrais do campo, isto é, garantir os resultados esperados, atender bem seus clientes, tal como ocorreria em uma empresa privada "socialmente responsável”, ou ser "eficiente", como recomendou Secchi (2010), ainda que a pobreza seja elevada e/ou crescente.

Sobretudo, a centralidade da eficiência representa a crença de que é possível, a partir da otimização da gestão da máquina pública, se chegar em um equacionamento dos 
problemas sociais. Tanto é que Keinert (1994), Mezzomo e Laporta (1994), Peci et al. (2011), Silva et al. (2013) e Smolski et al. (2017) relacionam e estabelecem a década de 1990 como marco inicial do período de consolidação da AP como campo científico, pelo seu aspecto gerencialista. Não obstante, a crise atual não corrobora com essa crença, pois os problemas sociais encontram-se em aprofundamento, a despeito de tanta "gestão".

Não é acidental que Fadul, Silva e Silva (2012), sustentem que o tratamento de temas que consideram como "fora da área" (ciência política, sociologia, etc.) seriam "falta de identificação própria do campo" (SILVA et al., 2013, p. 5) e uma dificuldade da AP se estabelecer enquanto disciplina. Silva et al. (2013, p. 8) afirmam que "necessita-se, portanto, de uma delimitação, direcionando os estudos para que contemplem de fato os interesses da administração pública, evitando a produção científica sem foco". Fica a dúvida: quais seriam os interesses da AP?

Inobstante a importância desses autores para o campo, suas perspectivas ideológicas e científicas não possibilitam perscrutar as reais causas da "fragilidade teórica", e da “organização da administração pública como campo de saber no Brasil” (FADUL, MACALLISTER e SILVA, 2014, p. 1352), não sem assumir, de partida, a tendência da ciência moderna de parcialização do conhecimento, que no atendimento às necessidades de produção e reprodução do (mais)valor, tende à perda da concepção de totalidade e à tornarse um obstáculo para a tomada de consciência dos problemas sociais que permeiam a realidade.

Destaquemos algumas constatações importantes, ainda que no plano das aparências: i) o foco principal da produção científica se concentra na análise de técnicas de gestão, gestão social de políticas públicas, reformas administrativas e avaliação de políticas públicas, ou seja, são gerencialistas (PECI et al., 2011; RIBEIRO, 2014). ii) os estudos revelam uma tendência à naturalização da forma política do Estado capitalista, pela opção de não questioná-las (FLEURY, 2003, HOCAYEN-DA-SILVA et al., 2008; JUSTEN e GURGEL, 2015; SMOLSKI et al., 2017). 
Como desdobramento imediato destas constatações, indicamos que o conhecimento produzido revela uma tendência a ater-se à superficialidade no tratamento das dinâmicas sociais fundamentais que permeiam os problemas sociais. Sobretudo porque na produção científica analisada vê-se que não se busca na particularidade sua lógica interna e suas ligações com a universalidade, quando muito, o predicado empírico oferece elementos para pequenas ampliações dos modelos e construtos analíticos com a inserção de um ou outro aspecto ou instância. Vê-se, assim, tentativas de se evitar as contradições objetivas da dinâmica social.

Ademais, tais pesquisas contribuem para naturalizar de maneira mais direta e explícita a supremacia dos interesses privados, tanto no âmbito do Estado como nas relações sociais hodiernas de um modo mais amplo, uma vez que colocam a sociedade como abstração frente ao indivíduo e legitimam o acesso de grupos privados ao fundo público (do trabalho) à revelia do controle social, que, apesar de limitado, ainda é uma mediação participativa na resolução de problemas sociais.

\section{A CRÍTICA MARXIANA AO ESTADO E AS POSIÇÕES IDEOLÓGICAS}

Após a análise da produção do conhecimento levantada por outros autores fizemos outro levantamento para que pudéssemos investigar o campo a partir de outro critério, sua vinculação ideológica, considerando, conforme Vaisman (2010), a partir de Lukács, que não há, necessariamente, uma oposição entre ciência e ideologia, podendo, inclusive, coexistirem.

Conforme Mészáros (2008, p. 11), “a consciência social prática de todas essas sociedades [divididas em classes] não pode deixar de ser ideológica", ou seja, de que todas as determinações sociais práticas são marcadas por ideologias, incluindo as formas como o Estado é abordado cientificamente, de forma que toda teoria possui um pressuposto ideológico. Por isso, a este ponto, precisamos expor o papel do Estado a partir da análise marxiana. 
Karl Marx foi um crítico severo do Estado capitalista. Ele vivenciou o declínio da forma de Estado monárquica - controlado pelo rei e a aristocracia - e da formação do Estado capitalista - controlado pela classe revolucionária em ascensão: a burguesia -, estando, assim, em um momento importante de transformação social e atento aos processos sociais e econômicos que moldaram esta forma de Estado desde sua gênese. Portanto, para Marx, o Estado moderno é o meio pelo qual a burguesia mantém seus privilégios, ainda que para isso mediações diversas devam ser produzidas.

Considerando o Estado moderno do século XXI, não obstante o expressivo desenvolvimento das forças produtivas, o movimento de produção e reprodução do controle da coisa pública permanece sob a batuta dos capitalistas, ou seja, ainda que a ação do Estado se dê no âmbito da luta de classes, é a classe dominante que detém os meios de produção e igualmente o poder de controle sobre o Estado. Nesse quadro, a contradição da AP emana da própria natureza mediadora do Estado, uma vez que toda reforma gestionária com aparência social é guiada pelos interesses do capital, sejam eles imediatamente contingentes (de alguns estratos da classe burguesa e não de outros) ou mediação necessária (reprodução das condições de existência da classe burguesa).

O Estado moderno não é e nem pode ser a solução para os antagonismos sociais que permeiam a sociabilidade capitalista, como mencionamos na questão da erradicação da pobreza. Conforme Marx (2013; 2014; 2017), a lei geral da acumulação capitalista demonstra que a produção da riqueza depende da existência da pauperização, na dinâmica que relaciona o processo de trabalho com o processo de valorização, desse modo, simplificando o que não é nada simples, em sua teleologia, o Estado moderno é fundamental para a perpetuação do capitalismo, razão pela qual a emancipação humana só será possível também com a superação do Estado (MARX, 2011), dado seu papel no ciclo de reprodução capitalista.

Não obstante, nem todos os teóricos sustentam tal possibilidade, há o campo progressista que acredita no potencial do Estado de amenizar as contradições entre capital e trabalho. 
Mészáros (2008, p. 11) apresenta posições ideológicas em seu movimento de produção do conhecimento, que nos ajudam a compreender essas gradações de horizonte político frente às investigações científicas, "a diferença entre três posições ideológicas fundamentalmente distintas que têm sérias implicações para os tipos de conhecimento compatíveis com cada uma delas", são:

A primeira [...] apoia a ordem estabelecida com uma atitude acrítica, adotando e glorificando a contiguidade do sistema dominante - não importa se problemático ou contraditório - como o horizonte absoluto da própria vida social. A segunda, exemplificada por pensadores radicais como Rousseau, expõe, com êxito significativo, as irracionalidades da forma específica de sociedade de classe, sem dúvida anacrônica, que é rejeitada a partir de uma nova posição de vantagem, mas sua crítica é viciada pelas contradições de sua própria posição social - igualmente determinada pelas classes sociais, mesmo se historicamente mais avançadas. E a terceira, em contraste com as duas anteriores, questiona radicalmente a persistência histórica do próprio horizonte de classe, antevendo, como objetivo de sua intervenção prática consciente, a supressão de todas as formas de antagonismo de classes.

A partir dessa distinção elaboramos a seguinte classificação, buscando analisar a produção do conhecimento a respeito do Estado e da AP:

a) Primeira posição ideológica: Artigos de caráter gerencial, que não questionam a natureza contraditória do Estado e são conservadores pois visam a manutenção desta forma estatal.

b) Segunda posição ideológica: Artigos que identificam debilidades na dinâmica social de classes, que de certa forma não naturalizaram o Estado capitalista, mas que tem sua crítica reduzida ao caráter de sua manutenção e reforma.

c) Terceira posição ideológica: Artigos que questionam radicalmente a dinâmica social de classes e que tenham como horizonte de intervenção prática a superação/abolição do Estado.

Ressaltamos que não foi nossa intenção positivar tais classificações como enquadramentos, apenas sinalizar o horizonte de tratamento ideológico dado ao Estado a partir das categorias que temos levantado, por exemplo, naturalização do Estado, gerencialismo, eficiência, reforma, superação do Estado etc. Nossa intenção é menos de classificar e mais de apreender o horizonte que guia a produção do conhecimento em AP. Por isso, o fato de um artigo apontar uma determinada posição ideológica não significa que o(s) 
autor(es) sejam conservadores, reformistas ou revolucionários, apenas que um dado artigo especificamente apresentou tal posição.

Realizamos um levantamento de trabalhos publicados em anais de três eventos científicos da grande área de Administração: EnANPAD, EnAPG e EnEO e também na Revista de Administração Pública (RAP) no período de 1971 a 2017, visando contribuir com o aprofundamento da compreensão acerca da produção do conhecimento no campo da AP. Motta (2007) ratifica a posição privilegiada na RAP na disseminação do conhecimento sobre AP durante esse período. Vale ressaltar que a opção pela RAP se dá pelo fato de ser um dos principais e mais antigos periódicos nacionais, possuindo tradição na divulgação de pesquisas relacionadas à Administração Pública. Consideramos ser suficiente a análise deste periódico dado que esta pesquisa não possui, entre seus objetivos, a pretensão de análise quantitativa de volume de publicações. As palavras-chave utilizadas na busca foram: Estado Capitalista, Teoria do Estado, Marx, Burocracia, Crítica, Administração Pública, Política Pública, Gestão Pública e Estado. Em seguida, realizamos uma primeira triagem dos artigos por título e resumo.

Os artigos dos eventos EnANPAD, EnEO e EnAPG foram levantados no sítio da ANPAD, apresentando, 1.600, 1.132 e 1.052 artigos, respectivamente. Contudo, pela limitação da ferramenta de busca, alguns artigos se repetiram em diferentes palavras-chave o que permite uma margem de erro que não invalida a análise qualitativa que realizamos a seguir. Quanto à RAP, utilizamos a base do Spell e encontramos 2.272 artigos. 0 resultado desse levantamento é apresentado a seguir.

\section{AS POSIÇÕES IDEOLÓGICAS DA PRODUÇÃO CIENTÍFICA NA ADMINISTRAÇÃO PÚBLICA}

A maioria dos estudos realizados, seguindo tendência apontada anteriormente, indicam um viés gerencialista, que poderiam ser classificados na primeira posição ideológica. Assim, nossa triagem buscou selecionar para uma investigação mais aprofundada apenas os artigos que apresentassem outras perspectivas, seguindo a classificação de Mészáros (2008), 
artigos que estivessem de acordo com a segunda e a terceira posição ideológica, ou seja, que aparentemente partissem de alguma crítica ou desnaturalização do Estado, ou mesmo, que viessem a apresentar alguma perspectiva de sua superação.

Dos 6.056 artigos que foram triados inicialmente entre a RAP, EnEO, EnAPG e EnANPAD apenas 42 puderam ser considerados "não-gerencialistas", menos de 1\% dos trabalhos, isto é, as críticas ao Estado capitalista em sua gênese praticamente inexiste no campo da AP.

Tabela 1 - Quantitativo de artigos publicados nos eventos/periódico selecionados

\begin{tabular}{|l|c|c|c|c|c|}
\hline \multicolumn{1}{|c|}{ PERÍODO } & ANPAD & ENEO $^{*}$ & ENAPG $^{*}$ & RAP & TOTAL \\
\hline $1970-1979$ & 0 & 0 & 0 & 0 & $\mathbf{0}$ \\
\hline $1980-1989$ & 0 & 0 & 0 & 9 & $\mathbf{5}$ \\
\hline $1990-1999$ & 1 & 0 & 0 & 4 & 13 \\
\hline $2000-2009$ & 5 & 2 & 3 & 0 & $\mathbf{1 5}$ \\
\hline $2010-2017$ & 8 & 6 & 1 & $\mathbf{1 6}$ & $\mathbf{4 2}$ \\
\hline TOTAL & $\mathbf{1 4}$ & $\mathbf{8}$ & $\mathbf{4}$ & 3 & $\mathbf{5}$ \\
\hline
\end{tabular}

Fonte: Dados da pesquisa (2019).

* Surgiram apenas na década de 2000.

A primeira constatação é a de que apenas após a década de 1980 são publicados os primeiros artigos em uma perspectiva não-gerencialista, todos eles publicados na RAP, pioneira no espaço para discussões de distintas posições ideológicas. Dois dentre os nove artigos são do notável geógrafo marxista Milton Santos, classificados como segunda posição ideológica, pois embora haja uma certa crítica ao Estado, não chegam a inquirir sobre sua gênese.

Notemos que o período com o maior número de publicações na RAP foi o de transição de um Estado ditatorial para o assim chamado Estado democrático, que tem como marco a Constituição de 1988. Ou seja, um período político conturbado, marcado pela perseguição aos intelectuais e pela censura, mas também de grande resistência por parte deles, o que pode ser observado pelo volume de trabalhos publicados. 
Entrementes, lembremo-nos que durante a década de 1970 e o começo dos anos 1980, o pensamento marxista foi rechaçado e perseguido pelos órgãos de censura e controle do Estado. Assim, é curioso notar a ínfima incidência de artigos que investiguem o período do estatismo ditatorial na década de 1990 em diante. 0 que pode ter ocorrido?

Isto é, após a formação da República e o retorno do Estado moderno democrático na década de 1990, sobretudo a partir de 1995 (Reforma do Estado), observamos uma diminuição na produção científica alinhada à segunda e à terceira posição ideológica. Isso acontece justamente no período que Justen e Gurgel (2015) e Smolski et al. (2017) apontam como sendo o de maior crescimento e impulso da produção de conhecimento científico pela área. Contudo, se tomarmos a produção considerando os eventos, notamos o crescimento das publicações nas últimas duas décadas (13 em 2000 e 15 artigos em 2010), o que sugere o estabelecimento do Estado moderno democrático e republicano no Brasil como "única forma de Estado possível”.

Nós já havíamos apontando o crescimento do viés empírico e gerencialista na AP, de modo que dos 28 artigos produzidos neste período, entre 2000 e 2017, apenas um único trabalho aludiu a superação do Estado, dada sua impotência quanto à resolução dos problemas sociais. Os demais, embora teçam alguma crítica, acreditam na possiblidade de reformar o Estado tornando-o, quiçá, mais justo e menos desigual. Mas, percebam, sem mexer na base da estrutura.

Tanto o volume da publicação desses artigos como sua tendência na busca por reformar o Estado sem inquiri-lo em sua gênese para encontrar suas determinações e mediações, corroboram com o que foi encontrado nos levantamentos bibliométricos realizados nos últimos anos (KEINERT, 1994; FLEURY, 2003; HOCAYEN-DA-SILVA, ROSSONI e FERREIRA-JÚNIOR, 2008; PECI et al., 2011; MARTINS, 2007; RIBEIRO, RODRIGUES e FORZANI, 2011; RIBEIRO, 2014; PAES-DE-PAULA et al., 2010); SILVA, TROTTMANN, COELHO e SARTI, 2013; JUSTEN e GURGEL, 2015; SMOLSKI et al., 2017), dada à predominância da gestão como forma de melhorar o Estado. 
Os 41 artigos classificados na segunda posição ideológica possuem as seguintes características: a) Resgatam as contribuições de autores críticos clássicos da área como: Maurício Tragtenberg, Alberto Guerreiro Ramos, Fernando Prestes Motta, José Henrique de Faria e Cláudio Gurgel; b) Partem de bases teóricas influenciadas pela sociologia, pela Escola de Frankfurt e por leituras marxistas, oferecendo um maior potencial explicativo a partir das diferentes abordagens para estabelecer uma crítica ao Estado burguês.

A guisa de exemplo, Faria e Meneghetti (2009; 2010) têm como foco a questão da burocracia. No primeiro trabalho rastreiam a gênese da organização burocrática em Tragtenberg e, no segundo, a forma como a burocracia se caracteriza como organização, poder e controle no pensamento de Tragtenberg e Motta, e demonstram a influência intelectual de Weber e do anarquismo em suas produções, suas críticas à burocracia e de como ela poderia ser abolida. Porém, Faria e Meneghetti $(2009 ; 2010)$ não chegam a apontar a superação do Estado e da dinâmica social baseada no capital, talvez por não ser o escopo daqueles trabalhos. Rosa Filho e Misoczky (2004) abordaram aspectos referentes as contribuições de Guerreiro Ramos, Maurício Tragtenberg e Prestes Motta voltado especificamente para o campo da regulação do Estado.

Em relação a segunda característica, podemos citar os trabalhos de Zwick (2014; 2015) e Teodósio e Alves (2006) que partem de referencial frankfurtiano. Zwick (2014) tece críticas aos estudos em administração pública e propõe a dialética negativa de Adorno como abordagem capaz de fundamentar uma epistemologia crítica. Já Zwick (2015) centra-se em aspectos da dialética negativa e explora o caráter de semiformação e de não idêntico para analisar algumas limitações do campo da Gestão Pública. Teodósio e Alves (2006) utilizam o referencial para fazer uma crítica ao "terceiro setor" propondo uma desconstrução de "narrativas gerencialista". Flores (2006) a partir da contribuição de Mészáros analisa o processo de privatização da água na Bolívia apontando para o comprometimento do Estado com a reprodução do capital, mas defende uma gestão pública da água pelo Estado sem reconhecer que esta gestão estatal não significa necessariamente, um rompimento com a reprodução do capital. Santos et al. (2007) propõem uma base metodológica para entender o 
sucesso e fracasso de políticas públicas em países periféricos, centrando a questão em torno da necessidade de uma forma gestão baseada na administração política. Ressaltamos o caráter crítico dos trabalhos mencionados, entretanto não propõem a superação do Estado burguês.

Na segunda posição ideológica, portanto, é possível observar que as investigações acerca dos problemas e contradições do Estado sugerem alternativas limitadas a sua reforma, sendo esse o elo comum das diversas abordagens utilizadas. Seja por meio de políticas redistributivas, mudanças culturais, formas de participação, crítica à burocracia e alternativas a semiformação. As contradições que envolvem capital e trabalho são abordadas de modo velado. Porém, como sustenta Misoczky (2004, p. 2), são contribuições de suma importância, "Afinal, a produção acadêmica tem um papel crítico a cumprir, especialmente ao considerar e desopacificar processos históricos e sociais de construção de naturalizações e reificações.”.

A terceira posição ideológica, por sua vez, apoia-se na necessidade de superação do Estado capitalista e de impotência [Ohnmacht] da Administração Pública (MARX, 2010). Encontramos apenas 1 artigo que poderia ser considerado como nesta posição em eventos e nenhum na RAP, trata-se do trabalho de Paço-Cunha (2012), em que o autor realiza uma crítica à alternativa webero-marxista tragtenberguiana, apontando seus limites e trazendo contribuições do materialismo marxiano e sua incompatibilidade com o projeto weberiano. Essa lacuna demonstra a importância de pesquisas que apresentem um contraponto radical ao conhecimento que vem sendo produzido, tencionando-o e forçando-o a deixar a superficialidade do empirismo vulgar.

Paço-Cunha (2012, p. 4) sustenta que a análise da organização produtiva é capaz de revelar concretamente a função mediativa do Estado na reprodução social da exploração da força de trabalho, “(...) the identity between capitalist State and enterprise by which the ideal type of bureaucratic organization is constituted establishes a specific obliteration of capitalrelation (Kapitalverhältnisse) and mystification of capitalist mode of production, precisely what Marx wanted to reveal, criticize and transform." 
Portanto, Paço-Cunha (2012), no horizonte de sua crítica, aponta para a superação do Estado capitalista a partir da superação da sociabilidade engendrada nas relações de produção guiadas pela valorização do valor, o que distingue da posição adotada por Faria e Meneghetti (2009; 2010) que, baseada em Tragtenberg e Motta, se traduz na alternativa autogestionária no horizonte de superação da burocracia, ao menos nesses trabalhos.

Em resumo, o número reduzido de artigos que compõem a segunda e a terceira posição nos traz uma questão importante: é possível utilizar e propor novas técnicas de gestão para o Estado brasileiro sem antes compreender sua formação social e sem dimensionar o processo histórico de formação do Estado capitalista?

Sim, é possível, até porque a aplicação de uma técnica no modelo de gestão capitalista vigente visa, sobretudo, um objetivo: a "eficiência" na gestão dos recursos, e muitas vezes o alcance desse objetivo não depende de análises sócio-históricas da realidade. É por isso que o Estado moderno é tratado cada vez mais de forma naturalizada e a-histórica e que o positivismo e o empirismo vulgar se consolidam nas pesquisas realizadas, pois ao estudarem casos concretos em suas particularidades aparentes, tratam o sintoma do problema, mas não atuam visando a superação das condições que o gestaram. Entretanto, como buscamos expor no decorrer desse trabalho, tal perspectiva é incapaz de resolver os problemas reais desses tempos.

\section{CONSIDERAÇÕES FINAIS}

0 caminho que percorremos ao longo deste trabalho para atingir o objetivo de perscrutar o conhecimento produzido na Administração Pública, no período entre 1970 até 2017, partindo do pressuposto que o Estado moderno corresponde a uma mediação determinante na sociabilidade capitalista, nos revelou que há uma lacuna no campo da AP quanto a um tratamento radical da questão da coisa pública. Afinal, qual o papel da ciência se não contribuir com a melhoria nas condições de vida no mundo? 
Constatamos que tem sido recorrente, entre diversos intelectuais que se dedicam aos problemas do Estado e da coisa pública, a busca por uma consolidação do campo enquanto disciplina. Tal busca revela por um lado, que as propostas teóricas, metodológicas e epistemológicas, assim como a dimensão técnica que emerge no campo, enfrentam problemas diante da realidade cotidiana, a consolidação que os autores procuram alcançar tem como centro a dimensão gnosiológica, ou seja, a elevação da posição subjetiva, da posição do pesquisador, do construto teórico-técnico diante da realidade efetiva (FERRAZ, CHAVES e FERRAZ, 2018). No final das contas, muda-se a forma de gerir e avaliar, mas não se questiona a dinâmica social.

Por outro lado, essa é mais uma face da impotência [Ohnmacht] e também da potência da AP, o movimento de proposição de uma nova teoria, técnica, epistemologia, paradigma, para se alcançar a excelência operacional das funções do Estado e da coisa pública, são insuficientes para acompanhar o movimento da realidade efetiva, pois parte da naturalização do Estado moderno e relegação do movimento histórico-material, caracterizando-se, assim, como uma verdadeira Cama de Procusto. A produção do conhecimento nesses moldes representa a perda da noção de totalidade, através, por exemplo, da produção de técnicas e discursos a ponto de instrumentalizar os interesses capitalistas, que são particulares à determinadas classes sociais, como se fossem universais.

Essa dimensão de relegação da realidade efetiva também se manifesta no fato de que quase não existe esforço no âmbito da produção do conhecimento analisado de entender o estado atual das coisas no que tange aos seus nexos fundamentais. 0 foco da administração pública tem sido, em maior medida, garantir que sejam atendidos os interesses capitalistas para a expansão da acumulação de capital sobre as mercadorias, vide as contrarreformas trabalhista e previdenciária, sem o devido tratamento por parte dos pesquisadores do campo.

Portanto, sustenta-se que a produção científica e a atividade produtiva tem sido, no geral, convergentes a ponto de se fundir, pois a ciência no modo de produção capitalista é utilizada “como simples meio para fins predeterminados, externos, alienados.” (MÉSZÁROS, 2006, p. 98). Nesse caminho, o conhecimento científico produzido pode ser um mero recurso 
técnico ideológico para as ações do Estado capitalista, um meio "neutro" de justificar a submissão do Estado destes tempos aos preceitos da gestão empresarial.

Tal constatação é reforçada pelo fato de que os gestores do Estado, em função de sua posição de mediadores, precisam conhecer e detectar ao menos os problemas mais latentes da sociedade civil e que são resultantes da própria dinâmica social do capitalismo. Sendo assim, precisam dispor de meios para "resolver" e/ou apaziguar esses problemas sociais diversos sem se afastar dos interesses capitalistas, que, por sua vez, visam manter a lógica do capital. Desse modo, no âmbito da luta de classes, ocasionalmente o Estado necessita atender de forma imediata alguns interesses contingentes da classe trabalhadora.

Contudo, pelo fato do Estado não atender, sempre, de forma imediata, os interesses dos capitalistas, e atender, em certas circunstâncias, esses interesses por meio da resolução das demandas dos trabalhadores, é que não se pode considerá-lo como mero bureau da burguesia, tratando-se, portanto, de uma esfera bem mais complexa e que merece o tratamento científico devido.

Apreendemos com essa investigação que os pesquisadores, em sua grande maioria, procuram resolver os problemas sociais atuais isentando-se de entender suas origens, as contradições da lógica do capital e da sociabilidade capitalista, assim como os conflitos oriundos da mediação da esfera política. Contentam-se com a dimensão instrumental de reforma da gestão do Estado, novos modelos burocráticos, propostas de participação social e de alternância no poder político em prol de uma boa gestão da coisa pública entre outras panaceias para a resolução dos males sociais que afligem, sobretudo, a classe trabalhadora na dinâmica social do capital. A face de impotência [Ohnmacht] da AP é ocultada predominantemente na produção do conhecimento, o que contribui para a perpetuação do Estado capitalista dado a potência da AP em mediar o interesse econômico.

Ademais, é preciso atestar, outra vez, a condição de naturalização do Estado e de escassez de discussão sobre o que se convencionou chamar de teoria do Estado dentro da literatura do campo assim como do papel da crítica na área de Administração pública. 
Percebemos que esta lacuna existe e que a condição de naturalização do Estado moderno se efetiva por meio da predominância de produções científicas com tendência a centrar suas análises nas abordagens gerenciais de técnicas e avaliações, sendo uma sugestão para pesquisas futuras a constante necessidade de recuperação do pensamento crítico radical.

Como alternativa ao estatuto científico que aqui expomos, sugerimos que um passo importante para o alcance de uma "verdadeira finalidade humana" que vislumbre uma mudança radical precede principalmente da existência de análises que questionem a constituição histórica de formação do Estado capitalista, pois são os conflitos entre a impotência [Ohnmacht] e a irresolubilidade dos problemas sociais, além da potência organizativa para atividades comuns e para o alcance do interesse econômico capitalista que regem as funções da Administração Pública, sendo necessário portanto seu tensionamento para que se possa considerar possiblidades concretas de uma sociabilidade substantivamente humanizante.

Por fim, Paço-Cunha (2016) alerta para a importância da consciência de classe na formação do administrador para além do capital, fato este significativo pois, como aponta Ferraz (2016, p. 85), "Estado e Capital objetivam produzir uma consciência de classe burguesa na classe trabalhadora". Apenas com uma consciência da realidade concreta, das contradições reais que nela operam, das mediações entre Estado e Capital, que será possível se pensar em uma "coisa pública" verdadeiramente centrada nos interesses coletivos, ou melhor, se poderá pensar em uma "coisa" produto da própria sociabilidade humana posta a serviço - e, por conseguinte, gerida - da humanização da humanidade.

\section{REFERÊNCIAS}

COELHO, F. de S. História do ensino de administração pública no Brasil (1854-2006): antecedentes, ciclos e a emergência do campo de públicas. Brasília: Enap, 2019.

DYE, T. R. Mapeamento dos modelos de análise de políticas públicas. In: F. G. HEIDEMANN, F. G., SALM, J. F (Orgs.). Políticas Públicas e desenvolvimento: bases epistemológicas e modelos de análise. Brasília: Editora Universidade de Brasília, 2009. 
ENGELS, F. Sobre a questão da moradia. São Paulo: Boitempo, 2015.

FADUL, E. M. C., COELHO, F. de S., COSTA, F. L. da e GOMES, R. C. Administração pública no Brasil: reflexões sobre o campo de saber a partir da Divisão Acadêmica da Associação Nacional de Pós-Graduação e Pesquisa em Administração (2009-2013). Revista de Administração Pública (RAP), v. 48, n. 5, 1329-1354, 2014.

FADUL, E. M. C., MAC-ALLISTER, M. A. e SILVA, L. P. Ensaiando interpretações e estratégias para o campo da administração pública no Brasil. Revista de Administração Pública, v. 46, n. 6, 1436-1458, 2012.

FARIA, J. H. de, MENEGHETTI, F. K. Gênese e estruturação da organização burocrática na obra de Maurício Tragtenberg. In: Anais do XXXIII Encontro da ANPAD. São Paulo: Anpad, 2009.

. Burocracia como organização, poder e controle. In: Anais do XXXIV Encontro da ANPAD. Rio de Janeiro: Anpad, 2010.

FERRAZ, D. L. da S. A Administração de recursos humanos como conhecimento que constitui uma consciência de classe para o capital. Revista Brasileira de Administração Política, v. 9, n. 2, 65-87, 2016.

. Projetos de geração de trabalho e renda e a consciência de classe dos desempregados.

Revista Organizações e Sociedade (O\&S), v. 22, n. 72, 123-141, 2015. FERRAZ, D. L. da S., CHAVES, R. H. S. e FERRAZ, J. de M. Para além da epistemologia: reflexões necessárias para o desenvolvimento do conhecimento. REAd. Revista Eletrônica de Administração, v. 24, n. 2, 1-30, 2018.

FLEURY, S, BLOCH, R., BRAVO, R. e BICUDO, V. Análise do perfil dos artigos publicados na Revista de Administração Pública - RAP - no período 1992-2002. Rio de Janeiro: Eaesp/FGV, 2003.

FLORES, R. K. Mercantilização da água e ativação dos limites absolutos do capital: a guerra da água pelas lentes de Mészáros. In: Anais do XXX EnANPAD. Salvador: Anpad, 2006.

HEIDEMANN, F. G. Do sonho de progresso às políticas de desenvolvimento. In: F. G. HEIDEMANN, SALM, J. F. Políticas Públicas e desenvolvimento: bases epistemológicas e modelos de análise. Brasília: Editora Universidade de Brasília, 2009.

HOCAYEN-DA-SILVA, A. J, ROSSONI, L., e FERREIRA-JÚNIOR, I. Administração pública e gestão social: a produção científica brasileira entre 2000 e 2005. Revista de Administração Pública (RAP), v. 42, n. 4, 655-680, 2008.

HOWLeTt, M., RAMESH, M. e PERL, A. Política Pública: seus ciclos e subsistemas: uma abordagem integradora. Rio de Janeiro: Elsevier, 2013. 
JUSTEN, A., GURGEL, C. Cursos de Administração: a dimensão pública como sujeito excluído. Cadernos EBAPE. BR, v. 13, n. 4, 852-871, 2015.

KEINERT, T. M. M. Os paradigmas de administração pública no Brasil (1900 - 1992). Revista de Administração de Empresas (RAE), São Paulo, v. 34, n. 3, 41-48, 1994.

SECCHI, L. Políticas Públicas: conceitos, esquemas de análise, casos práticos. São Paulo: CENGAGE Learning, 2010.

MARTINS, P. E. M. Revisitando os clássicos da RAP. Revista de Administração Pública (RAP), v. 41, n. spec., 49-65, 2007.

MARX, K. Glosas críticas ao artigo "'O rei da Prússia e a reforma social'. De um prussiano". In: MARX, K., e ENGELS, F. Lutas de classes na Alemanha. São Paulo: Boitempo, 2010.

Guerra civil na França. São Paulo: Boitempo, 2011.

O capital: crítica da economia política: livro I: o processo de produção do capital. São Paulo: Boitempo, 2013.

O capital: crítica da economia política: livro II: o processo de circulação do capital. São Paulo: Boitempo, 2014.

O capital: crítica da economia política: livro III: o processo global da produção capitalista. São Paulo: Boitempo, 2017.

MÉSZÁROS, I. A montanha que devemos conquistar: reflexões acerca do Estado. São Paulo: Boitempo, 2015.

. A teoria da alienação em Marx. São Paulo: Boitempo, 2006.

. Filosofia, ideologia e ciência social. São Paulo: Boitempo, 2008.

. Para além do capital: rumo a teoria da transição. São Paulo: Boitempo, 2011.

MEIRELLES, H. L., FILHO, J. E. B. e BURLE, C. R. Direito Administrativo brasileiro. São Paulo: Malheiros, 2016.

MENY, I., THOENING, J. C. Las políticas públicas. Barcelona: Ariel, 1992.

MEZZOMO, T. M., LAPORTA, C. B. A RAP e a evolução do campo de administração pública no Brasil. Revista de Administração Pública, v. 28, n. 4, 73-94, 1994. 
MISOCZKY, M. C. A. Uma defesa da reflexão teórico crítica na pesquisa e prática da administração pública: In: Anais do I Encontro Nacional de Administração Pública e Governança. Rio de Janeiro: ANPAD, 2004.

MOTTA, P. R. A modernização da administração pública brasileira nos últimos 40 anos. Revista de Administração Pública (RAP), v. 41, n. espec., 87-96, 2007.

PACHECO, R. S. Administração Pública nas revistas especializadas - Brasil, 1995-2002. Revista de Administração de Empresas (RAE), v. 43, n. 4, 63-71, 2003.

PAÇO-CUNHA, E. Ensino de Administração política e consciência de classe. Revista Brasileira de Administração Política, v. 9, n. 2, 33-64, 2016.

. Critical notes on (Weberian) marxist study of bureaucracy. In: Anais do VII Encontro de Estudos Organizacionais da ANPAD. Curitiba: Anpad, 2012.

PAES-DE-PAUlA, A. P., MARANHÃO, C. M. S. de A., BARRETO, R. de O. e KLECHEN, C. F. A Tradição e a Autonomia dos Estudos Organizacionais Críticos no Brasil. Revista de Administração de Empresas (RAE), v. 50, n. 1, 10-23, 2010.

PECI, A., RIBEIRO, A. J. G., RODRIGUES, F. B. S. e FORZANI, M. Paradigmas orientadores da pesquisa em administração pública no contexto brasileiro. In: Anais do XXV Encontro da ANPAD. Rio de Janeiro: Anpad, 2011.

PIRES, V., SILVA, S. de A. M., FONSECA, S. A., VENDRAMINI, P. e COELHO, F. S. Dossiê - Campo de Públicas no Brasil: definição, movimento constitutivo e desafios atuais. Revista de Administração Pública e Gestão Social, v. 6, n. 3, 110-126, 2014.

RIBEIRO, H. C. M. Doze anos de estudo da Revista de Administração Pública à luz da bibliometria e da rede social. Revista de Ciências Administrativas, v. 20, n. 1, 137-167, 2014.

ROSA FILHO, D. de S., MISOCZKY, M. C. A regulação no contexto brasileiro: reflexões inspiradas em Guerreiros Ramos, Maurício Tragtenberg e Fernando Prestes Motta. In: Anais do I Encontro Nacional de Administração Pública e Governança. Rio de Janeiro: ANPAD, 2004.

SANTOS, R. S., RIBEIRO, E. M., GOMES, F. G., SANTOS, L. C. dos, RIBEIRO, M. M, SANTOS, T. C. S., CARIBE, D. A., SOUTO, I. M. I. e SILVA JÚNIOR, C. D. da. Compreendendo a natureza das políticas do Estado capitalista. Revista de Administração Pública (RAP), v. 41, n. 5, 819$834,2007$. 
SCHNEIDER, A. L. Pesquisa avaliativa e melhoria da decisão política: evolução, história e guia prático. In: HEIDEMANN, F. G., SALM, J. F. Políticas Públicas e desenvolvimento: bases epistemológicas e modelos de análise. Brasília: Editora Universidade de Brasília, 2009.

SilVA, V. C., TROTTMANN, P., COElho, F. de S. e SARTI, F. M. A Produção Científica em Administração Pública no Brasil: descrição e análise de alguns resultados de uma investigação para o período 2000-2010. In: Anais do XXXVII Encontro da ANPAD. Rio de Janeiro: ANPAD, 2013.

SMOLSKI, F. M. da S., DALCIN, D., VISENTINI, M. S., BAMBERG, J. e KERN, J. S. Análise do perfil da produção científica da Revista de Administração Pública (RAP) no período de 2003-16. Revista de Administração Pública (RAP), v. 51, n. 6, 1139-1163, 2017.

TEODÓSIO, A. dos S. de S., ALVES, M. A. Teoria crítica e a desnaturalização do terceiro setor: a urgência de novas sínteses. In: Anais do IV Encontro de Estudos Organizacionais da ANPAD. Rio de Janeiro: ANPAD, 2006.

ZWICK, E. Por uma epistemologia crítica aos studos em Administração Pública: In: Anais do XXXVIIII Encontro da ANPAD. Rio de Janeiro: ANPAD, 2014.

- Introdução à crítica dialética negativa da gestão pública brasileira: a constelação colonialidade em suas bases da recusa do não idêntido. In: Anais do XXXIX Encontro da ANPAD. Rio de Janeiro: ANPAD, 2015.

VAISMAN, E. A ideologia e sua determinação ontológica. Verinotio - Revista on-line de educação e ciências humanas, v. 12, n. 6, 40-64, 2010. 